\title{
Applying Analytic Network Process to the Selection of Construction Projects
}

\author{
Jeng-Hsiang Lin*, Chien-Jou Yang \\ Department of Architecture, Hwa Hsia University of Technology, Taiwan \\ Email: "hsiang@cc.hwh.edu.tw
}

Received 30 December 2015; accepted 26 February 2016; published 1 March 2016

\begin{abstract}
Selecting a construction project is relatively complex as it involves multi-criteria decision-making (MCDM). To solve this problem, this study used the fuzzy Delphi method to identify six key factors of influence on selection outcomes and established evaluation criteria based on these factors. After employing analytic network process (ANP) to identify relationships between the objective, the evaluation criteria and the candidate projects, this study developed a decision-making model to resolve the difficulty of selecting an optimum construction project and conducted weighted analysis of the candidate projects using the quantitative procedures of ANP. Lastly, an empirical case study was used to verify the proposed method. The results of this study show that ANP can be used to build an effective decision-making model capable of analyzing candidate construction projects and selecting the optimal one.
\end{abstract}

\section{Keywords}

Analytic Network Process, Fuzzy Delphi Method, Construction Project, MCDM

\section{Introduction}

Construction companies are often faced with the challenge of selecting the most suitable option from a number of potential construction projects. As small to medium construction companies are unable to simultaneously undertake multiple projects due to limited resources, they must choose to invest in the project that is most feasible and beneficial to the business (optimum project).

Selecting a construction project is relatively complex as it involves multi-criteria decision-making (MCDM). The selection of construction projects considers factors such as: profit, financial risk, resources, technical ability, management capacity, environment impact, legislative requirements, contract, and business reputation. These factors serve as evaluation criteria, assisting construction companies in selecting optimum projects. But how important are these evaluation criteria to reaching the right decision? Are there any mutual relationships of influence among these criteria? And if so, how do these relationships affect the decision-making outcome? These are issues worthy of further exploration.

Recent studies [1]-[3] have proposed various approaches to the selection of construction contracts and the

\footnotetext{
${ }^{*}$ Corresponding author.
} 
feasibility of these methods has been verified through empirical research. Saaty developed the analytic network process (ANP) [4] to solve the problem of MCDM; this tool has been widely applied to decision-making problems in various fields, particularly in the selection of industrial projects. First, the unstructured problem is deconstructed through qualitative analysis. The problem is then structured in accordance with the relationships between clusters. Lastly, an expert survey is conducted and the results processed using quantitative analysis. The candidate projects are then ordered by priority on which basis a final decision is reached. Cheng and Li (2005) [3] were the first to use ANP in the selection of construction projects. However, Cheng and Li's model does not consider the relationships of mutual influence among the issues described above.

This study employed the fuzzy Delphi method to conduct a questionnaire survey of academics and experts in relation to specific construction projects. We then developed evaluation criteria for candidate projects and employed the qualitative procedures of ANP to establish the relationships between evaluation criteria, and candidate projects, and thereby a decision-making model for the selection of construction projects was constructed. Lastly, we conducted weighted analysis of the candidate projects, thereby ordering the projects by priority.

\section{Methodology}

\subsection{Evaluation Criteria}

The Delphi method has been widely used to generate forecasts in technology, education, and other fields. The method is based on a structured process of collecting and distilling knowledge from a group of experts by means of a series of questionnaires interspersed with controlled opinion feedback. Kaufmanm and Gupta (1988) [5] developed a triangular fuzzy function for the purpose of studying the Delphi function. Ishikawa et al. (1993) [6] used the concepts of cumulative frequency distribution and fuzzy integration to convert expert opinions into fuzzy numbers, resulting in the fuzzy Delphi method. Jeng (2001) [7] modified the fuzzy Delphi method by using double triangular fuzzy numbers to integrate expert opinions and then testing for consistency among the opinions using the gray zone test.

This study employed the modified fuzzy Delphi method proposed by Jeng to identify assessment factors for construction projects and established evaluation criteria for candidate projects based on these factors. The relevance of each assessment factor was scored on a scale of 0 - 10. A higher score indicates a greater influence on project selection outcomes. The operational stages of the modified fuzzy Delphi method are as follows.

Stage 1: Collect the fuzzy interval values of relevance scores.

This study collected the interval values of the relevance scores assigned by experts to each evaluation criterion. The minimum interval value (most conservative cognitive value) is indicated by $C$, while the maximum value (most optimistic cognitive value) is indicated by $O$; $a$ is the optimal representative value as determined by experts (subjective cognitive value). $C^{i}, O^{i}$ and $a^{i}$ respectively represent the minimum value, maximum value, and subjective cognitive value of the relevance score for evaluation criterion $i$.

Stage 2: Eliminate extreme values.

This study calculated the mean and standard deviation of the minimum value, maximum value, and subjective cognitive value of evaluation criterion $i$. Extreme values that fell beyond the range of mean $\pm 2 *$ standard deviation were eliminated.

Stage 3: Determine the triangular fuzzy number for the relevance scores of assessment factors.

This study calculated the following:

1) minimum value $C_{L}^{i}$, geometric mean $C_{M}^{i}$ and maximum value $C_{U}^{i}$ of the most conservative cognitive value $\left(C^{i}\right)$ with respect to the relevance of evaluation criterion $i$;

2) minimum value $O_{L}^{i}$, geometric mean $O_{M}^{i}$ and maximum value $O_{U}^{i}$ of the most optimistic cognitive value $\left(O^{i}\right)$ with respect to the relevance of evaluation criterion $i$;

3) minimum value $a_{L}^{i}$, geometric mean $a_{M}^{i}$ and maximum value $a_{U}^{i}$ of the subjective cognitive value $\left(a^{i}\right)$ of experts.

Based on the above we established the triangular fuzzy numbers for the minimum value $\left(C_{L}^{i}, C_{M}^{i}, C_{U}^{i}\right)$ and maximum value $\left(O_{L}^{i}, O_{M}^{i}, O_{U}^{i}\right)$ of the relevance score of evaluation criterion $i$ (see Figure 1).

Stage 4: Test for consistency.

The gray zone test was used to test for consistency among the opinions of experts (test value $Z^{i}=\left(O_{M}^{i}-C_{M}^{i}\right)$ $\left.-\left(C_{U}^{i}-O_{L}^{i}\right)\right)$.

1) When $C_{U}^{i}>O_{L}^{i}$ and $Z^{i} \geqq 0$, this indicates expert opinions are converging (consistent). 


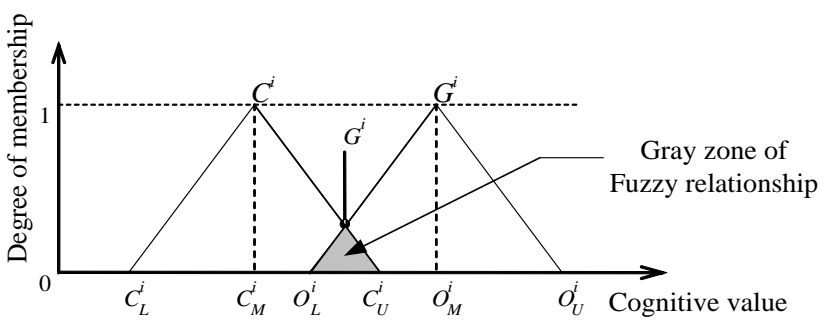

Figure 1. Double triangular fuzzy numbers.

2) When $C_{U}^{i}<O_{L}^{i}$ and $Z^{i}<0$, this indicates expert opinions are inconsistent. At this point a second survey of this specific evaluation criterion must be conducted.

Stage 5: Calculate the value of consensus among experts.

In Figure 1, the cognitive value corresponding to the intersection point of $C^{i}$ and $O^{i}$ is the value of consensus among experts (indicated by $G^{i}$ ) in relation to the relevance score of evaluation criterion $i$. The higher the value of $G$ is, the higher the consensus among experts of the significance of this assessment factor.

Stage 6: Select evaluation criteria.

This study sets $G=6.0$ as the threshold value for selecting evaluation criteria. Only those assessment factors with a $G$ value exceeding the threshold value were selected.

\subsection{Analytic Network Process}

Employing both qualitative and quantitative analysis, ANP provides a systemized process of analysis that determines the weight of each criterion, which in turn determines the relevance of each criterion and the potential for successfully reaching the objective.

Using a network approach, ANP structures a problem into a hierarchical format. Apart from its hierarchical analysis function, ANP can also be used to analyze feedback relationships between different levels and interdependent relationships among elements on the same level. The qualitative and quantitative procedures of ANP are described in [4]. This study conducts a questionnaire survey of experts, in our case a group of construction professionals, then conduct pairwise comparison. Using the nine-point priority scale developed by Saaty, we obtained the following three types of weighted values:

1) the relative importance of each evaluation criterion to the objective of decision-making;

2) the relative importance of each candidate project to specific criteria;

3 ) interdependent relationships among criteria to specific groups of elements.

Then, construct the initial supermatrix $\Omega$ with multiple sub-matrices comprising the priority vectors calculated and obtain the weighted supermatrix $\mathrm{W}$ by unitizing each column in the initial supermatrix. The sum of all elements in a column in a weighted supermatrix is 1 . Calculate the limit supermatrix by raising the weighted supermatrix to the power of $2 k+1$ with $k \rightarrow \infty$ (i.e. $\lim _{k \rightarrow \infty} \mathrm{W}^{2 k+1}$ ). The weighted values corresponding to each candidate project are derived from the first column of the limit supermatrix.

\section{Empirical Study}

\subsection{Case Study}

A case study was used to verify the feasibility of applying the ANP approach developed by Saaty to selection of construction projects. Four different construction projects, labelled Projects A, B, C and D, were considered in this study. The background variables of these four projects are provided in Table 1.

\subsection{Evaluation Criteria}

Using Jeng's modified fuzzy Delphi method, this study identified key factors that influence the selection of construction projects and designated these factors as evaluation criteria for candidate projects. This study distributed 10 questionnaires to five industry professionals and five academics, which were all recovered as valid questionnaires. Six factors were identified as significant: environment, finance, operations, management, legislation and technology. These factors are described in Table 2. 
Table 1. Brief outline of candidate projects.

\begin{tabular}{|c|c|c|c|c|}
\hline \multirow{2}{*}{ Description } & \multicolumn{4}{|c|}{ Project } \\
\hline & $\mathbf{A}$ & B & C & D \\
\hline Location & Taipei City & Taichung City & New Taipei City & New Taipei City \\
\hline Gross floor area $\left(m^{2}\right)$ & 8000 & 9000 & 5400 & 11000 \\
\hline Building type & $\begin{array}{c}12 \text {-storey residential } \\
\text { building }\end{array}$ & $\begin{array}{c}10 \text {-storey commercial } \\
\text { building }\end{array}$ & $\begin{array}{l}\text { 7-storey residential } \\
\text { building }\end{array}$ & $\begin{array}{l}\text { 12-storey commercial } \\
\text { building }\end{array}$ \\
\hline Construction material & Reinforced concrete & Steel & Reinforced concrete & Steel reinforced concrete \\
\hline
\end{tabular}

Table 2. Assessment factors for construction projects.

\begin{tabular}{|c|c|}
\hline Assessment factor & Scope \\
\hline Environment (C1) & $\begin{array}{l}\text { Environmental considerations include public relations, environmental protection, geographical location, and } \\
\text { health and safety. }\end{array}$ \\
\hline Finance (C2) & Financial considerations include profit, budget control and risk-return ratio. \\
\hline Operations (C3) & $\begin{array}{l}\text { Operational considerations include allocation of personnel, demand for resources, project duration, and } \\
\text { company objectives and policy. }\end{array}$ \\
\hline Management (C4) & Management considerations include capacity to execute project and problem-solving capability. \\
\hline Legislation (C5) & Legislative considerations include relevant legislation, codes and contractual clauses. \\
\hline Technology (C6) & Technological considerations include professional technical capacity and technological upgrades. \\
\hline
\end{tabular}

Table 3 presents the statistical results of the modified FDM questionnaire survey, illustrating that the consensus values for the six assessment factors all exceeded the threshold of 6.0, i.e., experts agreed that these factors were sufficiently relevant to decision making.

\subsection{Weighted Values of Relative Importance for Evaluation Criteria}

Following interviews with experts confirming the mutual interdependence of the evaluation criteria, the qualitative processes of ANP are illustrated in the 3-tier framework presented in Figure 2. The first tier is the decision-making objective, the second the six mutually interdependent evaluation criteria, and the third comprises the candidate projects. The ANP structural model and corresponding initial supermatrix are shown in Figure 3. In the initial supermatrix, w1 indicates a $6 \times 1$ matrix; W2 is a 6x6 matrix; W3 is a $4 \times 6$ matrix, and I is the unit matrix.

Table 4 integrates the pairwise comparison matrix, consistency test and relative importance weights of the six evaluation criteria. The results in Table 4 show that when construction companies select projects, the evaluation criteria are weighted in order of importance as follows: environment (0.209), finance (0.187), operations (0.176), legislation (0.172), management (0.146) and technology (0.110). Interestingly, environment has the highest weight while technology presents the lowest. This means that environment is the most important factor.

\subsection{Ordering of Candidate Projects}

The case study comprised 4 candidate projects (Projects A-D). Table 5 shows the pairwise comparison matrix, consistency test and relative importance weights of each project in relation to environment. The $C R$ value of 0.05 is less than 0.1, indicating that the expert survey results were consistent. The last column of Table 5 shows the relative importance weights of the four candidate projects in relation to environment. The weight of environment was greatest in Project B and lowest in Project C, indicating that Project B has the lowest impact on environment and Project $C$ the strongest. In addition, Project B had the highest weight for finance. Project B also had the highest weight for operations. The weight of the management factor was greatest in Project A. Project D had the highest weight for legislation. Lastly, the weight of the technology factor was greatest in Project A. 


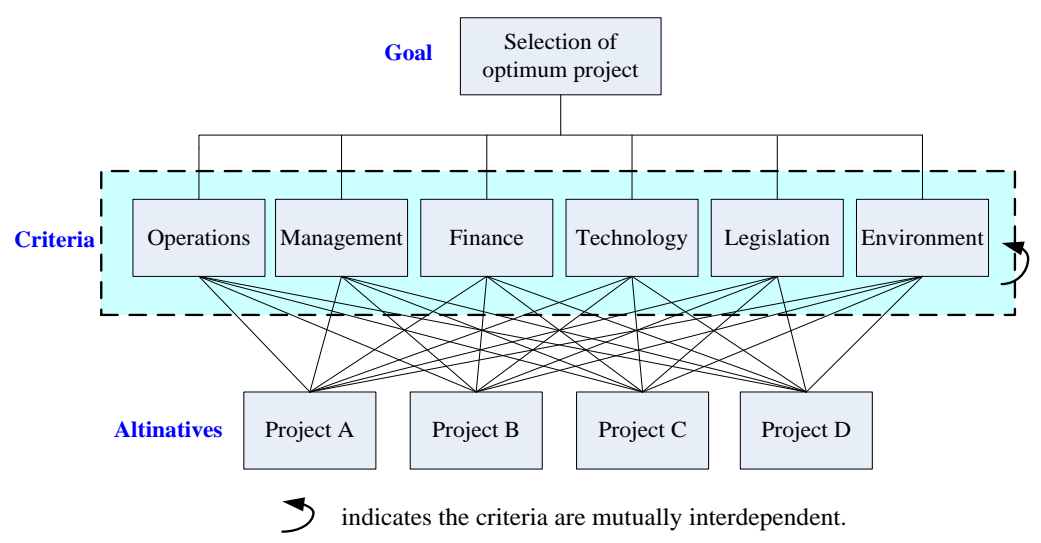

Figure 2. Hierarchical structure of project selection.

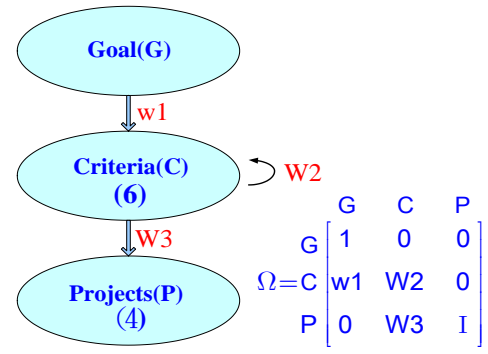

Figure 3. Structural ANP model.

Table 3. Modified FDM statistical analysis and selection of assessment criteria.

\begin{tabular}{|c|c|c|c|c|c|c|c|c|c|c|c|}
\hline \multirow{2}{*}{ Assessment factors } & \multicolumn{2}{|c|}{$\begin{array}{c}\text { Minimum } \\
\text { value, } C^{i}\end{array}$} & \multicolumn{2}{|c|}{$\begin{array}{c}\text { Maximum } \\
\text { Value, } O^{i}\end{array}$} & \multicolumn{2}{|c|}{$\begin{array}{c}\text { Single value, } \\
a^{i} \\
\end{array}$} & \multicolumn{3}{|c|}{$\begin{array}{c}\text { Geometric } \\
\text { mean }\end{array}$} & \multirow{2}{*}{$\begin{array}{c}\text { Test value } \\
Z^{i}\end{array}$} & \multirow{2}{*}{$\begin{array}{c}\text { Consensus value } \\
G^{i}\end{array}$} \\
\hline & $\min$ & $\max$ & $\min$ & $\max$ & $\min$ & $\max$ & $C^{i}$ & $O^{i}$ & $a^{i}$ & & \\
\hline Environment (C1) & 4 & 8 & 7 & 10 & 6 & 9 & 5.54 & 8.44 & 7.13 & 1.89 & 7.37 \\
\hline Finance (C2) & 4 & 8 & 6 & 10 & 5 & 9 & 5.66 & 8.32 & 7.11 & 0.66 & 7.00 \\
\hline Operations (C3) & 4 & 7 & 7 & 9 & 5 & 8 & 4.82 & 7.76 & 6.44 & 2.95 & 7.00 \\
\hline Management (C4) & 4 & 7 & 6 & 10 & 5 & 8 & 5.07 & 8.02 & 6.5 & 1.94 & 6.51 \\
\hline Legislation (C5) & 4 & 8 & 6 & 9 & 5 & 8 & 5.18 & 7.75 & 6.64 & 0.57 & 6.76 \\
\hline Technology (C6) & 4 & 6 & 6 & 8 & 5 & 7 & 4.54 & 6.94 & 5.63 & 2.41 & 6.00 \\
\hline
\end{tabular}

Table 4. Pairwise comparison matrix, consistency test and relative importance weights of the six evaluation criteria. [w1]

\begin{tabular}{cccccccc}
\hline [w1] & Environment & Finance & Operations & Management & Legislation & Technology & Weight \\
\hline Environment & 1.0 & 1.3 & 1.2 & 1.3 & 1.2 & 1.8 & 0.209 \\
Finance & 0.77 & 1.0 & 1.1 & 1.3 & 1.2 & 1.7 & 0.187 \\
Operations & 0.83 & 0.91 & 1.0 & 1.2 & 1.1 & 1.6 & 0.176 \\
Management & 0.77 & 0.77 & 0.83 & 1.0 & 0.8 & 1.3 & 0.146 \\
Legislation & 0.83 & 0.83 & 0.91 & 1.25 & 1.0 & 1.7 & 0.172 \\
Technology & 0.56 & 0.59 & 0.63 & 0.77 & 0.59 & 1.0 & 0.110 \\
& & & & & & &
\end{tabular}




\begin{tabular}{|c|c|c|c|c|c|c|c|c|c|c|c|}
\hline & Goal & $C 1$ & $C 2$ & C3 & C4 & C5 & C6 & A & B & C & $D$ \\
\hline Goal & 1.000 & 0.000 & 0.000 & 0.000 & 0.000 & 0.000 & 0.000 & 0.000 & 0.000 & 0.000 & 0.000 \\
\hline$C 1$ & 0.209 & 0.337 & 0.036 & 0.107 & 0.065 & 0.107 & 0.041 & 0.000 & 0.000 & 0.000 & 0.000 \\
\hline$C 2$ & 0.187 & 0.049 & 0.373 & 0.269 & 0.246 & 0.272 & 0.071 & 0.000 & 0.000 & 0.000 & 0.000 \\
\hline C3 & 0.176 & 0.095 & 0.230 & 0.365 & 0.102 & 0.172 & 0.156 & 0.000 & 0.000 & 0.000 & 0.000 \\
\hline$C 4$ & 0.146 & 0.067 & 0.181 & 0.150 & 0.378 & 0.047 & 0.119 & 0.000 & 0.000 & 0.000 & 0.000 \\
\hline$C 5$ & 0.172 & 0.259 & 0.060 & 0.069 & 0.172 & 0.338 & 0.256 & 0.000 & 0.000 & 0.000 & 0.000 \\
\hline C6 & 0.110 & 0.193 & 0.120 & 0.040 & 0.037 & 0.064 & 0.357 & 0.000 & 0.000 & 0.000 & 0.000 \\
\hline A & 0.000 & 0.330 & 0.327 & 0.210 & 0.379 & 0.240 & 0.399 & 1.000 & 0.000 & 0.000 & 0.000 \\
\hline$B$ & 0.000 & 0.350 & 0.339 & 0.390 & 0.286 & 0.261 & 0.092 & 0.000 & 1.000 & 0.000 & 0.000 \\
\hline C & 0.000 & 0.085 & 0.101 & 0.102 & 0.094 & 0.115 & 0.251 & 0.000 & 0.000 & 1.000 & 0.000 \\
\hline$D$ & 0.000 & 0.235 & 0.233 & 0.298 & 0.241 & 0.384 & 0.258 & 0.000 & 0.000 & 0.000 & 1.000 \\
\hline
\end{tabular}

Figure 4. Initial supermatrix.

Table 5. Pairwise comparison matrix, consistency test and relative importance weights of each project in relation to evaluation criteria. [W3]

\begin{tabular}{cccccc}
\hline [W3] & A & B & C & D & Weight \\
\hline Environment & & & & & 0.330 \\
A & 1.0 & 0.833 & 4.4 & 1.4 & 0.350 \\
B & 1.2 & 1.0 & 1.0 & 1.35 & 0.085 \\
C & 0.227 & 0.25 & 2.50 & 1.0 & 0.235 \\
D & 0.714 & 0.74 & & \\
& & $C R=0.05$ & & \\
\hline
\end{tabular}

Table 6. Pairwise comparison weights of the interdependent relationships of evaluation criteria. [W2]

\begin{tabular}{ccccccc}
\hline [W2] & Environment & Finance & Operations & Management & Legislation & Technology \\
\hline Environment & 0.337 & 0.036 & 0.107 & 0.065 & 0.107 & 0.041 \\
Finance & 0.049 & 0.373 & 0.269 & 0.246 & 0.272 & 0.071 \\
Operations & 0.095 & 0.230 & 0.365 & 0.102 & 0.172 & 0.156 \\
Management & 0.067 & 0.181 & 0.150 & 0.378 & 0.047 & 0.119 \\
Legislation & 0.259 & 0.060 & 0.069 & 0.172 & 0.338 & 0.256 \\
Technology & 0.193 & 0.120 & 0.040 & 0.037 & 0.064 & 0.357 \\
\hline
\end{tabular}

Table 6 shows the pairwise comparison weights of the interdependent relationships among evaluation criteria. From Tables 4-6 we can obtain the initial supermatrix (Figure 4). The values in the weighted supermatrix are column stochastic. Note that the values in each column of the weighted supermatrix add up to a value of 1 . If the values in the weighted supermatrix are mutually interdependent, then by repeated squaring we can obtain a converged limit supermatrix and the priority weights for the four candidate projects, which are as follows: Project A (0.307), Project B (0.3), Project D (0.276), and Project C (0.117). Therefore, the construction firm should elect to undertake Project A.

\section{Conclusions}

Based on the methods of FDM and ANP, this study presents a comprehensive framework for making the best selection from a range of candidate projects for a construction company. The framework systematically identifies the most significant criteria for project selection, constructs a decision model and sets up a consistent evalu- 
ation standard for facilitating a group decision process. Based on the proposed framework, a decision-making process was developed, through the consideration of the interdependent relationships of evaluation criteria. The results show that the evaluation criteria are weighted in the order of importance as follows: environment (0.209), finance (0.187), operations (0.176), legislation (0.172), management $(0.146)$ and technology $(0.110)$. Environment is the most important factor in the selection of an optimum construction project.

\section{References}

[1] Okpala, D.C. (1991) Evaluation and Selection of Construction Projects in Nigeria. Construction Management and Economics, 9, 51-61. http://dx.doi.org/10.1080/01446199100000005

[2] Wong, E.T.T., Norman, G. and Flanagan, R. (2000) A Fuzzy Stochastic Technique for Project Selection. Construction Management and Economics, 18, 407-414. http://dx.doi.org/10.1080/01446190050024824

[3] Cheng, E.W.L. and Li, H. (2005) Analytic Network Process Applied to Project Selection. Journal of Construction Engineering and Management, 131, 459-466. http://dx.doi.org/10.1061/(ASCE)0733-9364(2005)131:4(459)

[4] Saaty, T.L. (1996) Decision Making with Dependence and Feedback: The Analytic Network Process. RWS Publications, Pittsburgh, Pennsylvania.

[5] Kaufmann, A. and Gupta, M.M. (1988) Fuzzy Mathematical Models in Engineering and Management Science. Elsevier Science Publishers, North-Holland, Amsterdam, N.Y.

[6] Ishikawa, A., Amagasa, T., Tamizawa, G., Totsuta, R. and Mieno, H. (1993) The Max-min Delphi Method and Fuzzy Delphi Method via Fuzzy Integration. Fuzzy Sets and Systems, 55, 241-253. http://dx.doi.org/10.1016/0165-0114(93)90251-C

[7] Jeng, T.B. (2001) Fuzzy Assessment Model for Maturity of Software Organization in Improving Its Staff's Capability. Ph.D. Dissertation, National Taiwan University of Science and Technology, Taipei, Taiwan. 